\title{
Effects of Blood Flow Restriction Training on Muscular Strength and Hypertrophy in Older Individuals: A Systematic Review and Meta-Analysis
}

\author{
Christoph Centner $^{1}\left[\right.$ [ $\cdot$ Patrick Wiegel ${ }^{1,2}$ (]) $\cdot$ Albert Gollhofer $^{1} \cdot$ Daniel König $^{1}$
}

Published online: 10 October 2018

(c) The Author(s) 2018, corrected publication 2018

\begin{abstract}
Background The combination of low-load resistance training with blood flow restriction (BFR) has recently been shown to promote muscular adaptations in various populations. To date, however, evidence is sparse on how this training regimen influences muscle mass and strength in older adults.

Purpose The purpose of this systematic review and meta-analysis was to quantitatively identify the effects of low-load BFR (LL-BFR) training on muscle mass and strength in older individuals in comparison with conventional resistance training programmes. Additionally, the effectiveness of walking with and without BFR was assessed.

Methods A PRISMA-compliant systematic review and meta-analysis was conducted. The systematic literature research was performed in the following electronic databases from inception to 1 June 2018: PubMed, Web of Science, Scopus, CINAHL, SPORTDiscus and CENTRAL. Subsequently, a random-effects meta-analysis with inverse variance weighting was conducted. Results A total of 2658 articles were screened, and 11 studies with a total population of $N=238$ were included in the metaanalysis. Our results revealed that during both low-load training and walking, the addition of BFR elicits significantly greater improvements in muscular strength with pooled effect sizes (ES) of 2.16 (95\% CI 1.61 to 2.70) and 3.09 (95\% CI 2.04 to 4.14), respectively. Muscle mass was also increased when comparing walking with and without BFR [ES 1.82 (95\% CI 1.32 to 2.32)]. In comparison with high-load training, LL-BFR promotes similar muscle hypertrophy [ES 0.21 (95\% CI -0.14 to 0.56$)]$ but lower strength gains [ES $-0.42(95 \% \mathrm{CI}-0.70$ to -0.14$)]$.

Conclusion This systematic review and meta-analysis reveals that LL-BFR and walking with BFR is an effective interventional approach to stimulate muscle hypertrophy and strength gains in older populations. As BFR literature is still scarce with regard to potential moderator variables (e.g. sex, cuff pressure or training volume/frequency), further research is needed for strengthening the evidence for an effective application of LL-BFR training in older people.
\end{abstract}

Christoph Centner and Patrick Wiegel have contributed equally.

Electronic supplementary material The online version of this article (https://doi.org/10.1007/s40279-018-0994-1) contains supplementary material, which is available to authorized users.

Christoph Centner

christoph.centner@sport.uni-freiburg.de

1 Department of Sport and Sport Science, University of Freiburg, Freiburg, Germany

2 Bernstein Center Freiburg, University of Freiburg, Freiburg, Germany 


\section{Key Points}

The results of the present systematic review and metaanalysis suggest that blood flow restriction (BFR) is an effective strategy for increasing the effects of low-load (LL) resistance training and walking on muscle mass and strength in older adults.

In comparison with high-load (HL) resistance training, LL-BFR training produces comparable changes in muscle mass but lower increases in muscular strength.

The addition of BFR to LL resistance training or walking is an effective exercise alternative for older populations, for whom a traditional HL training might be contraindicated due to comorbidities or high mechanical stress to bones and joints.

\section{Introduction}

In recent years, blood flow restriction (BFR) training has gained increasing attention in the scientific community [1-3]. By applying tourniquets or inflatable cuffs at the proximal portion of the limb, low-load BFR (LL-BFR) training (20-30\% one repetition maximum, 1RM) has been shown to promote muscular hypertrophy and strength increases comparable to what is typically seen following high-load (HL) training programmes with 70-85\% 1RM [4-6]. The advantage of low loads and thus reduced mechanical stress for joints and bones [7] is of particular interest for populations who are not capable of lifting near-maximum loads or for whom high loads may be contraindicated, such as in clinical rehabilitation.

In this context, particularly in elderly subjects, HL resistance training is often not feasible due to comorbidities such as coronary heart diseases, diabetes mellitus or musculoskeletal impairments [8-10]. With advancing age, the skeletal muscle mass decreases by as much as $3-8 \%$ per decade after the age of 30 [11]. The coexistence of both, a decrease in muscle mass and strength is termed sarcopenia [12] and has major functional and metabolic consequences, including an increased risk of falls and mortality $[13,14]$. With regard to demographic changes, especially in Western societies [15], it is increasingly important to identify suitable evidence-based interventions that counteract the functional decline occurring with progressive age.

To maximize the span of effective functioning with advancing age, exercise and nutritional interventions have been suggested as the cornerstones in the management of sarcopenia $[12,16]$. In particular, the prescription of longterm HL resistance training programmes has been shown to maintain and increase both muscle mass and strength [17-20]. However, these training regimens do not consider the high prevalence of comorbidities [8] and the decreased tolerance of mechanical stress in older individuals.

Although recent reviews have investigated the effects of LL-BFR training in athletes [21] and individuals with a clinical musculoskeletal condition [2], there is currently no systematic review summarizing the effects of LL-BFR in older adults. Thus, the aim of the present systematic review and meta-analysis is to assess the effects of LL-BFR training on muscle strength and muscle mass in older subjects and provide practical implications for the prevention and treatment of the age-induced decline in muscle mass and strength.

\section{Methods}

\subsection{Search Strategy}

This systematic review and meta-analysis followed the guidelines provided in the PRISMA statement [22] (Prospero registration number: CRD42018089980). For identification of relevant studies, a systematic literature search was performed by two researchers (CC \& PW). The following electronic databases were searched from inception to 1 June, 2018: PubMed, Web of Science, Scopus, CINAHL, SPORTDiscus and CENTRAL. The search string was created with two sections: the first encompassed synonyms for LL-BFR training while the second was composed of synonyms for the topic of aging. To ensure that at least one search term within one section was included in the results, all synonyms were connected with the operator 'OR' and both sections were connected with the operator 'AND'. Moreover, truncations and adjacency searching were used to find variations of the corresponding term and to restrict the results to specific ordered terms. Database searching was performed with no restrictions ('All field/All text' search) except in Scopus where the search was restricted to 'Title, Abstract, Keywords'.

The search was conducted independently by the two researchers using the following search string for all databases: "blood flow restriction" OR "occlusion training" OR "vascular occlusion" OR KAATSU OR "ischemi* training" AND old* OR elder* OR sarcopeni* OR "musc* atrophy".

Study information, including title and abstract, were exported from the databases and stored in a citation manager. Before further processing of the studies all duplicates were removed (for search process see Fig. 1). 


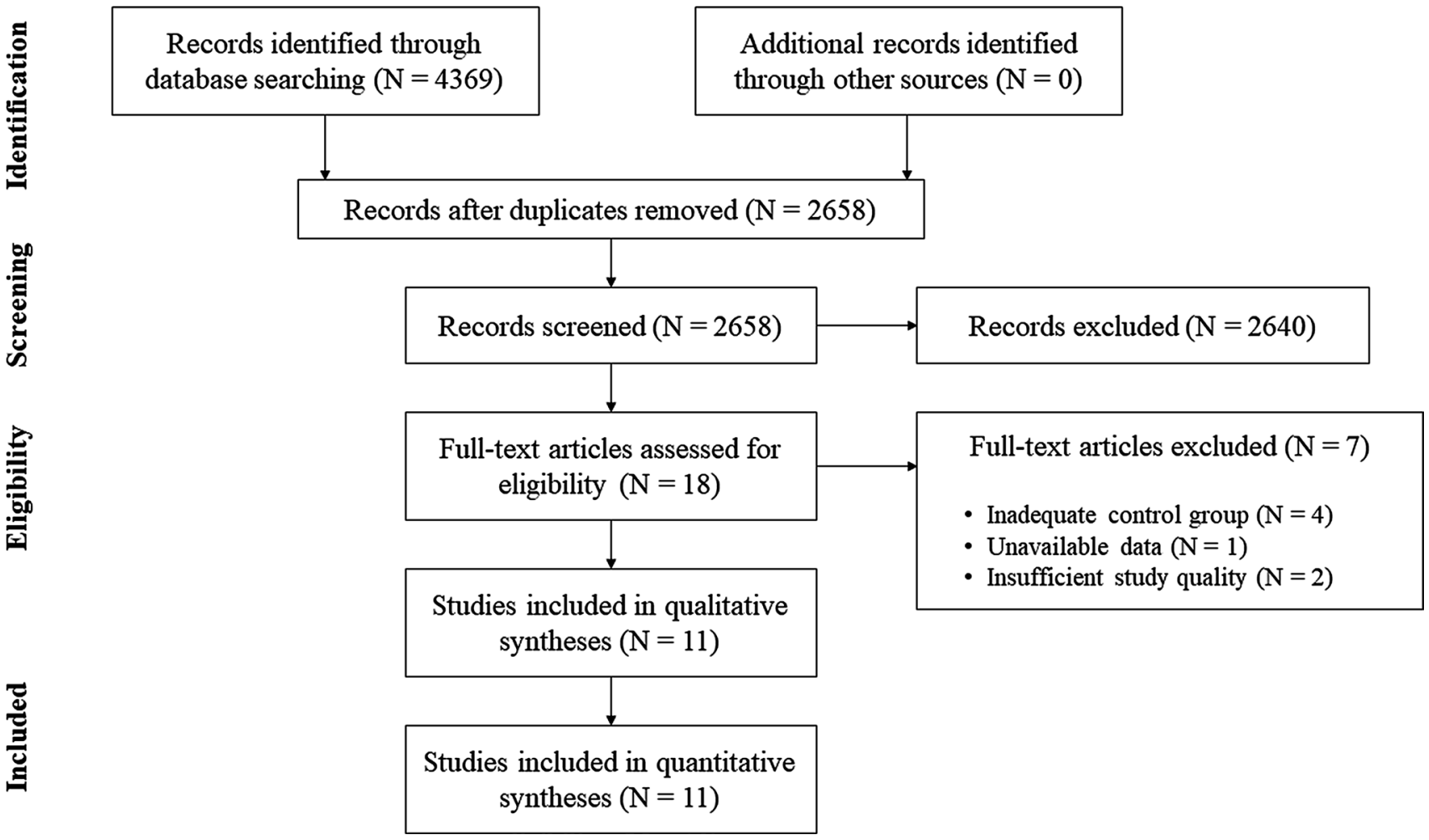

Fig. 1 Flow chart presenting the search process and study selection

\subsection{Inclusion and Exclusion Criteria}

All studies were screened and assessed for eligibility with regard to our inclusion and exclusion criteria, which were based on the PICOS principle (i.e. extracting population, intervention, comparison intervention, outcome measures and study design information) [23, 24]. Studies were considered relevant if (1) subjects were healthy older people (aged $>50$ years), (2) the study design allowed comparisons between resistance training with and without vascular occlusion [HL ( $>70 \% 1 \mathrm{RM})$ or LL $(<50 \% 1 \mathrm{RM})$ resistance training] or between walking with and without simultaneous BFR, (3) muscle mass and/or strength were assessed pre- and post-training.

Studies were not considered relevant if (1) participants had received a substance previously shown to result in muscle gains or (2) the manuscript was not written in the English language. Additionally, quality of reports was determined using the Physical Evidence Database (PEDro) scale, which is based on the Delphi list [25] (Electronic Supplementary Material Table S1). Studies with a score $<4$ were excluded from this systematic review. For each of the 11 items of the PEDro scale, two reviewers (CC \& PW) assessed the studies independently. In case of any discrepancy, a third reviewer (DK) evaluated the study to find a consensus.

\subsection{Data Extraction and Assessment of Reviewer Agreement}

After screening of the studies, all relevant considered articles were assessed for eligibility based on their full texts. At this stage, we extracted information about (1) population characteristics, (2) primary outcome measures, (3) methods, (4) exercise/interventional characteristics and (5) the main result of the study. When intervention effects were assessed at multiple time points, only the very last time point was considered (as post-training value). In case of incomplete raw data availability, we contacted the corresponding author of the manuscript or extrapolated the data from figures, if the authors could not be reached. All studies were assessed for inclusion in this systematic review independently by two researchers (CC and PW) based on the extracted information. If there were any disagreements about inclusion of a study, a third reviewer (DK) was consulted. The extracted data of included studies are depicted in Tables 1, 2, 3 and 4.

\subsection{Risk of Bias}

Following the instructions in the Cochrane Handbook for Systematic Reviews of Interventions [26], risk of bias was assessed using six criteria that were individually rated for each study. In this context, selection bias, performance bias, 


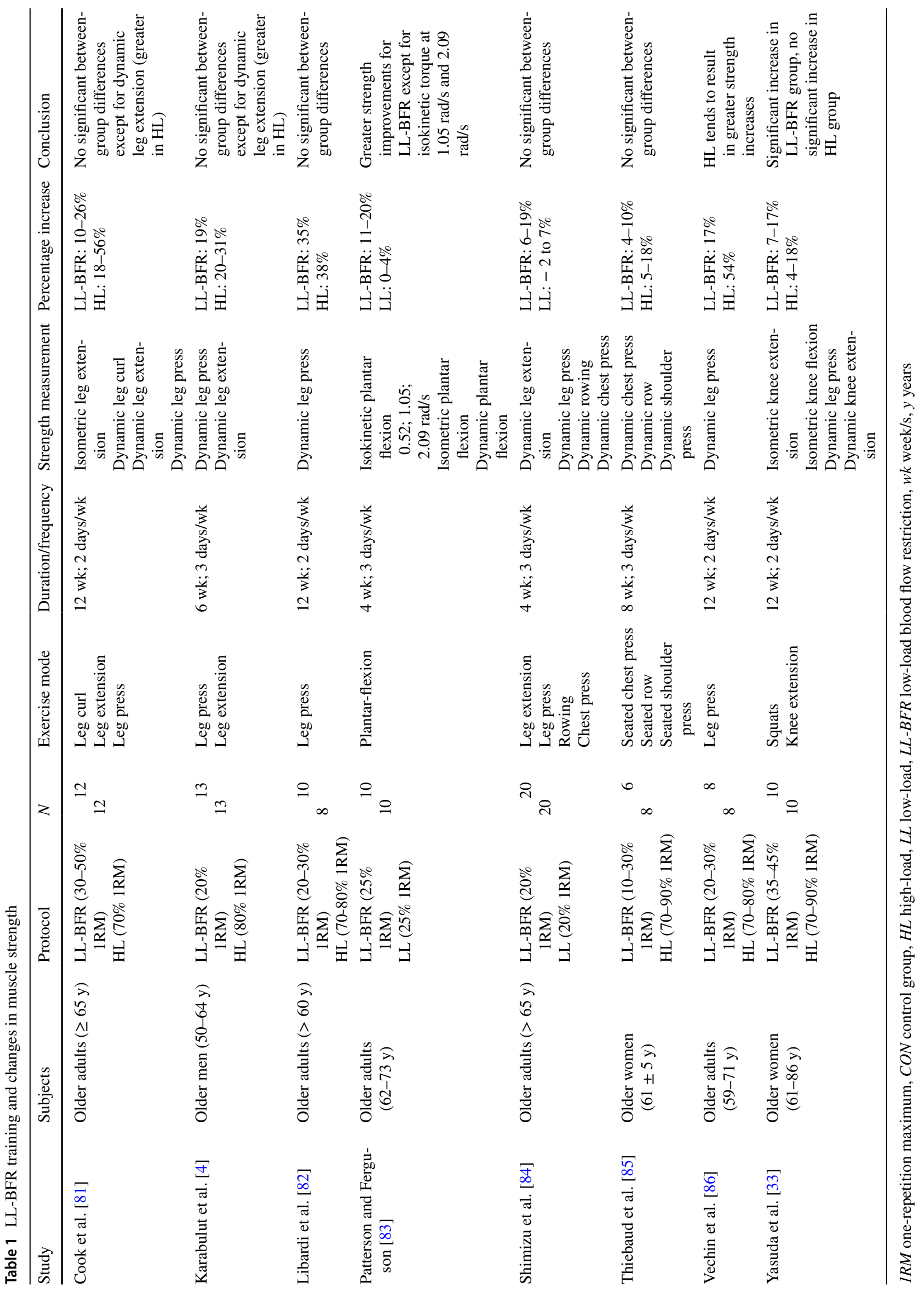


Table 2 LL-BFR training and changes in muscle mass

\begin{tabular}{|c|c|c|c|c|c|c|c|c|}
\hline Study & Subjects & Protocol & $N$ & $\begin{array}{l}\text { Exercise } \\
\text { mode }\end{array}$ & $\begin{array}{l}\text { Duration/ } \\
\text { frequency }\end{array}$ & $\begin{array}{l}\text { Muscle mass } \\
\text { assessment }\end{array}$ & $\begin{array}{l}\text { Percentage } \\
\text { increase }\end{array}$ & Conclusion \\
\hline $\begin{array}{l}\text { Cook et al. } \\
\text { [81] }\end{array}$ & $\begin{array}{l}\text { Older adults } \\
\quad(\geq 65 \mathrm{y})\end{array}$ & $\begin{array}{l}\text { LL-BFR (30-50\% } \\
\text { 1RM) } \\
\text { HL (70\% 1RM) }\end{array}$ & $12^{12}$ & $\begin{array}{l}\text { Leg curl } \\
\text { Leg exten- } \\
\text { sion } \\
\text { Leg press }\end{array}$ & $\begin{array}{l}12 \mathrm{wk} ; 2 \\
\text { days/wk }\end{array}$ & MRI & $\begin{array}{l}\text { LL-BFR: } \\
7 \% \\
\text { HL: } 6 \%\end{array}$ & $\begin{array}{l}\text { No significant } \\
\text { between-group } \\
\text { differences }\end{array}$ \\
\hline $\begin{array}{l}\text { Libardi et al. } \\
\text { [82] }\end{array}$ & $\begin{array}{l}\text { Older adults } \\
(>60 \mathrm{y})\end{array}$ & $\begin{array}{l}\text { LL-BFR (20-30\% } \\
\text { 1RM) } \\
\text { HL (70-80\% } \\
\text { 1RM) }\end{array}$ & $8^{10}$ & Leg press & $\begin{array}{l}12 \mathrm{wk} ; 2 \\
\text { days/wk }\end{array}$ & MRI & $\begin{array}{l}\text { LL-BFR: } \\
8 \% \\
\text { HL: } 7 \%\end{array}$ & $\begin{array}{l}\text { No significant } \\
\text { between-group } \\
\text { differences }\end{array}$ \\
\hline $\begin{array}{l}\text { Thiebaud } \\
\text { et al. [85] }\end{array}$ & $\begin{array}{l}\text { Older women } \\
(61 \pm 5 \mathrm{y})\end{array}$ & $\begin{array}{l}\text { LL-BFR (10-30\% } \\
\text { 1RM) } \\
\text { HL (70-90\% } \\
\text { 1RM) }\end{array}$ & $8^{6}$ & $\begin{array}{l}\text { Seated chest } \\
\text { press } \\
\text { Seated row } \\
\text { Seated } \\
\quad \text { shoulder } \\
\text { press }\end{array}$ & $\begin{array}{l}8 \mathrm{wk} ; 3 \\
\text { days/wk }\end{array}$ & $\begin{array}{l}\text { Ultrasound } \\
\text { Biceps brachii } \\
\text { Triceps brachii } \\
\text { Deltoid } \\
\text { Pectoralis } \\
\text { major } \\
\text { DEXA } \\
\text { Arm bone-free } \\
\text { LBM }\end{array}$ & $\begin{array}{l}\text { LL-BFR: } \\
3-17 \% \\
\text { HL: }-5 \text { to } \\
7 \%\end{array}$ & $\begin{array}{l}\text { No significant } \\
\text { between-group } \\
\text { differences }\end{array}$ \\
\hline $\begin{array}{l}\text { Vechin et al. } \\
\text { [86] }\end{array}$ & $\begin{array}{c}\text { Older adults } \\
(59-71 \mathrm{y})\end{array}$ & $\begin{array}{l}\text { LL-BFR (20-30\% } \\
\text { 1RM) } \\
\text { HL (70-80\% } \\
\text { 1RM) }\end{array}$ & 8 & Leg press & $\begin{array}{l}12 \mathrm{wk} ; 2 \\
\text { days/wk }\end{array}$ & MRI & $\begin{array}{l}\text { LL-BFR: } \\
6 \% \\
\text { HL: } 7 \%\end{array}$ & $\begin{array}{l}\text { Similar increases in } \\
\text { both groups }\end{array}$ \\
\hline $\begin{array}{l}\text { Yasuda et al. } \\
\text { [33] }\end{array}$ & $\begin{array}{l}\text { Older women } \\
(61-86 \text { y) }\end{array}$ & $\begin{array}{l}\text { LL-BFR (35-45\% } \\
\text { 1RM) } \\
\text { HL (70-90\% } \\
\text { 1RM) }\end{array}$ & $10^{10}$ & $\begin{array}{l}\text { Squats } \\
\text { Knee exten- } \\
\text { sion }\end{array}$ & $\begin{array}{l}12 \mathrm{wk} ; 2 \\
\text { days/wk }\end{array}$ & $\begin{array}{l}\text { MRI } \\
\text { Quadriceps } \\
\text { Adductors } \\
\text { Gluteus maxi- } \\
\text { mus } \\
\text { Hamstring }\end{array}$ & $\begin{array}{l}\text { LL-BFR: } \\
7 \%^{\mathrm{a}} \\
\text { HL: } 2 \%^{\mathrm{a}}\end{array}$ & $\begin{array}{l}\text { No significant } \\
\text { between-group } \\
\text { differences except } \\
\text { for quadriceps } \\
\text { CSA (greater in } \\
\text { LL-BFR) }\end{array}$ \\
\hline
\end{tabular}

${ }^{a}$ Values are only reported for the quadriceps muscle, since data for other muscle groups were not available

$1 R M$ one-repetition maximum, $C O N$ control group, CSA cross-sectional area, DEXA dual x-ray absorptiometry, $H L$ high-load, $L B M$ lean body mass, $L L-B F R$ low-load blood flow restriction, $M R I$ magnetic resonance imaging, $w k$ week/s, $y$ years

detection bias, as well as attrition and reporting bias were considered by the reviewers (Electronic Supplementary Material Figure S1). Additionally, to assess the evidence of publication bias, funnel plots were visually inspected for each outcome criterion (Electronic Supplementary Material Figures S2-S6).

\subsection{Synthesis of Results}

Percentage changes $\left[\left(\left(\mathrm{MEAN}_{\text {post }}-\mathrm{MEAN}_{\mathrm{pre}}\right) / \mathrm{MEAN}-\right.\right.$ pre $) \times 100$ ] of muscle strength and muscle mass were calculated for each study. In case of multiple assessment methods, the minimum and maximum mean value of each method were reported (Tables 1, 2, 3, 4).

\subsection{Statistical Analyses}

Statistical analyses were performed using RevMan (Review Manager Version 5.3, The Cochrane Collaboration, 2014). For calculating the standardized mean difference (SMD), the difference in pre- and post-intervention mean and standard deviation values of muscle mass and strength for all groups in each study were used. Since we partially observed considerable between-timepoint differences in $\mathrm{SD}_{\text {pre }}$ and $\mathrm{SD}_{\text {post }}$, $\mathrm{SD}_{\text {change }}$ was defined as $\mathrm{SD}_{\text {change }}=$ root square $\left[\left(\mathrm{SD}_{\mathrm{pre}}^{2} /\right.\right.$ $\left.\mathrm{N}_{\text {pre }}\right)+\left(\mathrm{SD}_{\text {post }} 2 / \mathrm{N}_{\text {post }}\right)$ [ 27]. A forest plot was created to present the SMD and $95 \%$ confidence intervals (CIs) of muscle mass and muscular strength for all respective comparisons. All analyses were conducted using a random effects model to account for measurement variability and heterogeneity among the studies. For each comparison, pooled effects sizes (ES) were calculated. Alpha level was therefore set to $p<0.05$. Data are reported as mean \pm standard deviation.

The assessment of the between-study heterogeneity was verified with the $I^{2}$ method, with an $I^{2}$ of $0-40 \%$ representing a low heterogeneity, 30-60\% representing a moderate heterogeneity and 50-90\% and $75-100 \%$ representing a substantial or considerable heterogeneity, respectively [26].

In total, five meta-analyses were conducted. First of all, the effects of LL-BFR training on muscle mass and strength were compared with HL training and LL training (analyses 1-3). A fourth and fifth comparison were performed to 
Table 3 BFR walking and changes in muscle strength

\begin{tabular}{|c|c|c|c|c|c|c|c|c|}
\hline Study & Subjects & Protocol & $N$ & Exercise mode & $\begin{array}{l}\text { Duration/fre- } \\
\text { quency }\end{array}$ & $\begin{array}{l}\text { Strength meas- } \\
\text { urement }\end{array}$ & $\begin{array}{l}\text { Percentage } \\
\text { increase }\end{array}$ & Conclusion \\
\hline $\begin{array}{l}\text { Clarkson et al. } \\
\text { [66] }\end{array}$ & $\begin{array}{l}\text { Older adults } \\
\quad(60-80 \mathrm{y})\end{array}$ & $\begin{array}{l}\text { BFR walking } \\
(4 \mathrm{~km} / \mathrm{h}) \\
\text { CON walking } \\
(4 \mathrm{~km} / \mathrm{h})\end{array}$ & $9^{10}$ & Walking & $\begin{array}{l}6 \text { wk; } 4 \text { days/ } \\
\text { wk }\end{array}$ & $\begin{array}{l}\text { 30-sec sit-to- } \\
\text { stand test }\end{array}$ & $\begin{array}{l}\text { BFR: } 28 \% \\
\text { CON: } 8 \%\end{array}$ & $\begin{array}{l}\text { Significantly } \\
\text { greater } \\
\text { strength } \\
\text { increases for } \\
\text { BFR }\end{array}$ \\
\hline $\begin{array}{l}\text { Ozaki et al. } \\
\text { [87] }\end{array}$ & $\begin{array}{l}\text { Older adults } \\
\quad(57-76 \mathrm{y})\end{array}$ & $\begin{array}{r}\text { BFR walking } \\
(45 \% \text { HRR }) \\
\text { CON walking } \\
(45 \% \text { HRR })\end{array}$ & $10^{13}$ & $\begin{array}{l}\text { Treadmill walk- } \\
\text { ing (20 min) }\end{array}$ & $\begin{array}{l}10 \text { wk; } 4 \text { days/ } \\
\text { wk }\end{array}$ & $\begin{array}{l}\text { Isokinetic knee } \\
\text { extension } \\
\text { Isokinetic knee } \\
\text { flexion }\end{array}$ & $\begin{array}{l}\text { BFR: } 9-15 \% \\
\text { CON: } 0-3 \%\end{array}$ & $\begin{array}{l}\text { Significantly } \\
\text { greater } \\
\text { strength } \\
\text { increases for } \\
\text { BFR except } \\
\text { for knee } \\
\text { extension }\end{array}$ \\
\hline $\begin{array}{l}\text { Ozaki et al. } \\
\text { [67] }\end{array}$ & $\begin{array}{l}\text { Older women } \\
(57-73 \text { y) }\end{array}$ & $\begin{array}{r}\text { BFR walking } \\
(45 \% \text { HRR }) \\
\text { CON walking } \\
(45 \% \text { HRR })\end{array}$ & $8^{10}$ & $\begin{array}{l}\text { Treadmill walk- } \\
\text { ing (20 min) }\end{array}$ & $\begin{array}{l}10 \text { wk; } 4 \text { days/ } \\
\text { wk }\end{array}$ & $\begin{array}{l}\text { Isometric knee } \\
\text { extension } \\
\text { Isokinetic knee } \\
\text { extension } \\
30 \% \mathrm{~s} ; 180 \% \mathrm{~s} \\
\text { Isokinetic knee } \\
\text { flexion } \\
30 \% \mathrm{~s} ; 180 \% \mathrm{~s}\end{array}$ & $\begin{array}{l}\text { BFR: } 3-22 \% \\
\text { CON: }-4 \text { to } \\
2 \%\end{array}$ & $\begin{array}{l}\text { Significantly } \\
\text { greater } \\
\text { strength } \\
\text { increases for } \\
\text { BFR except } \\
\text { for isometric } \\
\text { knee exten- } \\
\text { sion }\end{array}$ \\
\hline
\end{tabular}

$1 R M$ one-repetition maximum, $B F R$ blood flow restriction, $C O N$ control group, $H R R$ heart rate reserve, $w k$ week/s, $y$ years

Table 4 BFR walking and changes in muscle mass

\begin{tabular}{|c|c|c|c|c|c|c|c|c|}
\hline Study & Subjects & Protocol & $N$ & Exercise mode & $\begin{array}{l}\text { Duration/fre- } \\
\text { quency }\end{array}$ & $\begin{array}{l}\text { Muscle mass } \\
\text { assessment }\end{array}$ & $\begin{array}{l}\text { Percentage } \\
\text { increase }\end{array}$ & Conclusion \\
\hline $\begin{array}{l}\text { Ozaki et al. } \\
\text { [87] }\end{array}$ & $\begin{array}{c}\text { Older adults } \\
(57-76 \mathrm{y})\end{array}$ & $\begin{array}{r}\text { BFR walking } \\
(45 \% \text { HRR) } \\
\text { CON walking } \\
(45 \% \text { HRR })\end{array}$ & $10^{13}$ & $\begin{array}{l}\text { Treadmill walk- } \\
\text { ing (20 min) }\end{array}$ & $\begin{array}{l}10 \text { wk, } 4 \text { days/ } \\
\text { wk }\end{array}$ & MRI & $\begin{array}{l}\text { BFR: } 3 \% \\
\text { CON: } 0 \%\end{array}$ & $\begin{array}{l}\text { Significant } \\
\text { greater } \\
\text { muscle mass } \\
\text { increases for } \\
\text { BFR }\end{array}$ \\
\hline $\begin{array}{l}\text { Ozaki et al. } \\
\text { [67] }\end{array}$ & $\begin{array}{l}\text { Older women } \\
(57-73 \text { y) }\end{array}$ & $\begin{array}{r}\text { BFR walking } \\
\text { (45\% HRR) } \\
\text { CON walking } \\
\text { (45\% HRR) }\end{array}$ & $8^{10}$ & $\begin{array}{l}\text { Treadmill walk- } \\
\text { ing (20 min) }\end{array}$ & $\begin{array}{l}10 \text { wk, } 4 \text { days/ } \\
\text { wk }\end{array}$ & $\begin{array}{l}\text { MRI } \\
\text { Mid-thigh } \\
\text { (CSA) } \\
\text { Mid-quadri- } \\
\text { ceps (CSA) } \\
\text { Thigh (volume) } \\
\text { Quadriceps } \\
\text { (volume) }\end{array}$ & $\begin{array}{l}\text { BFR: } 3-4 \% \\
\text { CON: }-2 \text { to } \\
0 \%\end{array}$ & $\begin{array}{l}\text { Significant } \\
\text { greater } \\
\text { muscle mass } \\
\text { increases for } \\
\text { BFR }\end{array}$ \\
\hline
\end{tabular}

$B F R$ blood flow restriction, $C O N$ control group, CSA cross-sectional area, $H R R$ heart rate reserve, min minutes, MRI magnetic resonance imaging, $w k$ week/s, $y$ years

investigate the additional benefit of blood flow restriction in combination with walking exercise. In all analyses, multiple comparisons were included from several studies (e.g. dynamic and isometric strength measurements) in order to increase accuracy and thus generalization of our analyses. This is a common and accepted statistical method for metaanalysis [28].

\section{Results}

\subsection{Study Selection}

In total, from an initial 2658 studies, 11 were included in this systematic review and meta-analysis. From 18 studies, we assessed the full texts (for full search process see Fig. 1). After checking for eligibility of these articles based on our inclusion and exclusion criteria, we 
excluded studies that compared LL-BFR training with balance training [29], water-based exercise [30] or a nontraining control group [31,32]. Additionally, after the corresponding author could repeatedly not be contacted, muscle mass values from one study [33] and all outcome measures from another study were excluded from the meta-analyses [5]. Two more studies had to be excluded due to insufficient study quality (PEDro score $<4$ ) [34, 35].

\subsection{LL-BFR versus HL}

Six studies comparing the effects of LL-BFR and HL training on muscle strength were included in the metaanalysis (see Fig. 2). Given that several studies had multiple treatment outcome measures, a total of 14 comparisons were incorporated in the quantitative analysis. Between-group comparisons revealed significantly higher increases in muscle strength following HL $(24.0 \pm 16.2 \%)$ compared with LL-BFR training $(14.4 \pm 6.3 \%)$. The calculation of the meta-analysis showed a significant $(Z=2.96, p<0.01)$ pooled ES of $-0.42(95 \% \mathrm{CI}-0.70$ to -0.14$)$ in favour of HL. Heterogeneity was not significant with an $I^{2}$ of $18 \%(p=0.26)$.

Four studies with eight outcome measures investigated the effects of long-term LL-BFR and HL training on muscle mass (see Fig. 3). Averaged percentage increases of muscle mass were $6.2 \pm 5.1 \%$ and $4.2 \pm 4.2 \%$ in the
LL-BFR and HL groups, respectively. The weighted average ES was 0.21 (95\% CI - 0.14 to 0.56$)$ in favour of LLBFR training. However, this effect did not reach statistical significance $(Z=1.16, p=0.25)$. The calculation of $I^{2}$ showed a heterogeneity of $0 \%(p=0.86)$.

\subsection{LL-BFR Versus LL}

A total of two studies and nine comparisons measuring muscular strength following LL-BFR and LL training were included in this meta-analysis (see Fig. 4). Both studies used repetition matched protocols. Across all comparisons, LL-BFR training had an average percentage increase of $12.3 \pm 4.1 \%$ in muscle strength, compared with LL with $2.5 \pm 2.7 \%$. Quantitative analyses demonstrated significantly greater strength increases with LL-BFR compared with LL $(Z=3.79, p<0.001)$. The pooled ES was $0.86(95 \% \mathrm{CI}$ $0.42-1.30$ ). However, heterogeneity was considerably higher for this meta-analysis with $I^{2}=64 \%(p<0.01)$.

No study was identified comparing the effects of LL-BFR and LL on muscle mass.

\subsection{BFR and Walking}

Three studies (eight comparisons) assessed muscle strength changes following long-term BFR walking and walking with normal blood flow (see Fig. 5). Studies that combined walking with and without BFR showed percentage changes of $13.3 \pm 8.5 \%$ and $0.4 \pm 3.9 \%$ in muscular

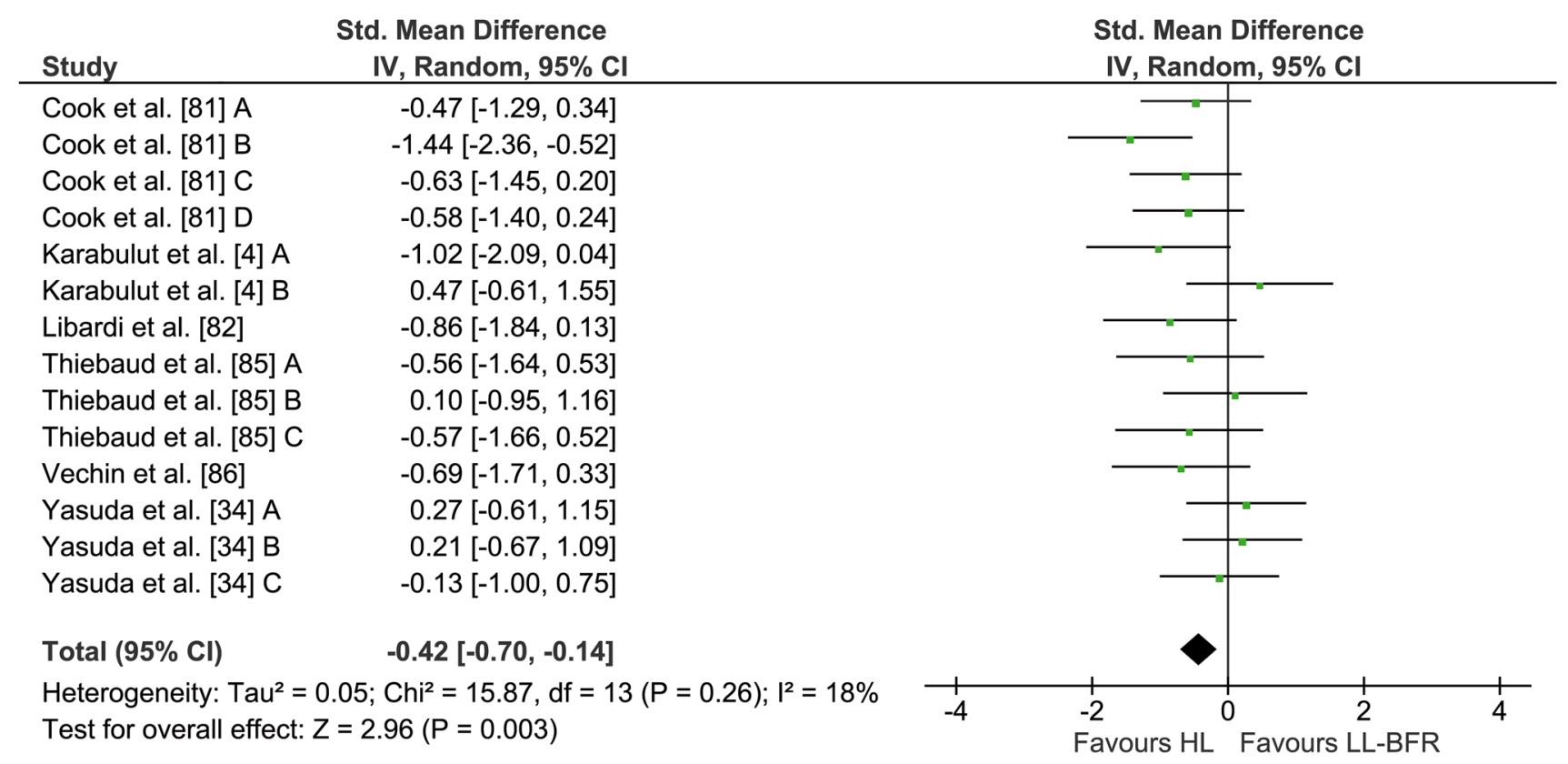

Fig. 2 Forest plot demonstrating the effects of LL-BFR versus HL training on muscular strength. Different letters for the same study represent different muscular strength assessment methods. $C I$ confidence interval, $H L$ high-load, $I V$ inverse variance, $L L-B F R$ low-load blood flow restriction, Random random effects model 


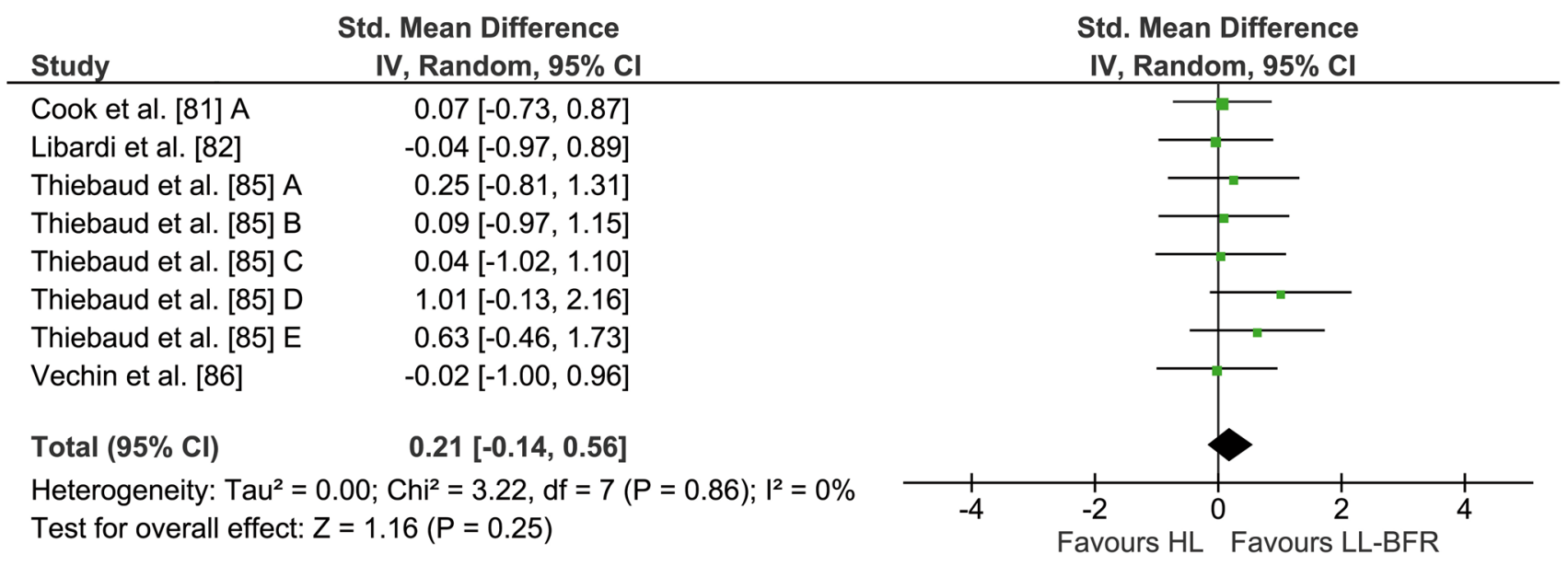

Fig. 3 Forest plot demonstrating the effects of LL-BFR versus HL training on muscle mass. Different letters for the same study represent different assessment methods for muscle mass. $C I$ confidence inter- val, $H L$ high-load, $I V$ inverse variance, $L L-B F R$ low-load blood flow restriction, Random random effects model

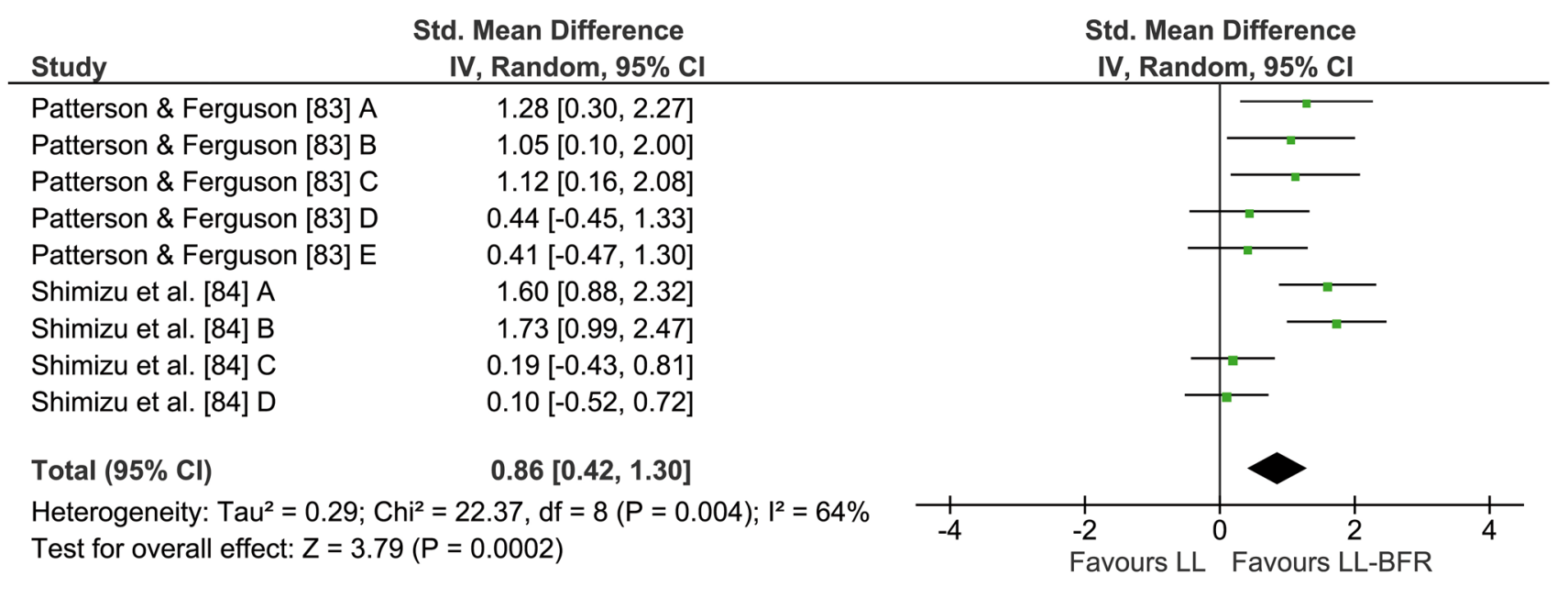

Fig. 4 Forest plot demonstrating the effects of LL-BFR versus LL training on muscular strength. Different letters for the same study represent different muscular strength assessment methods. $C I$ confidence interval, $I V$ inverse variance, $L L$ low-load, $L L-B F R$ low-load blood flow restriction, Random random effects model strength, respectively. Calculation of the meta-analysis revealed significantly greater strength increases $(Z=5.75$, $p<0.001)$ when walking was performed with partial vascular occlusion. The weighted average ES was 3.09 (95\% CI 2.04-4.14). $I^{2}$ for this analysis was $77 \%$ and demonstrated a high heterogeneity $(p<0.001)$.

In order to compare the effects of walking with and without BFR on muscle mass, two studies with a total of seven comparisons were included in the quantitative analysis (see Fig. 6). Mean muscle mass percentage gain was $3.0 \pm 0.4 \%$ for the BFR + walking group, with mean percentage changes of $-0.7 \pm 0.7 \%$ in walking with normal blood flow. Statistical examination revealed a significantly higher increase in muscle mass following BFR compared with normal walking $(Z=7.11, p<0.001)$. The average ES and $I^{2}$ were $1.82(95 \%$ CI $1.32-2.32)$ and $0 \%$ $(p=0.86)$, respectively.

\section{Discussion}

The main objective of the present systematic review and meta-analysis was to assess the effects of LL-BFR training on muscle mass and strength in older adults, compared 


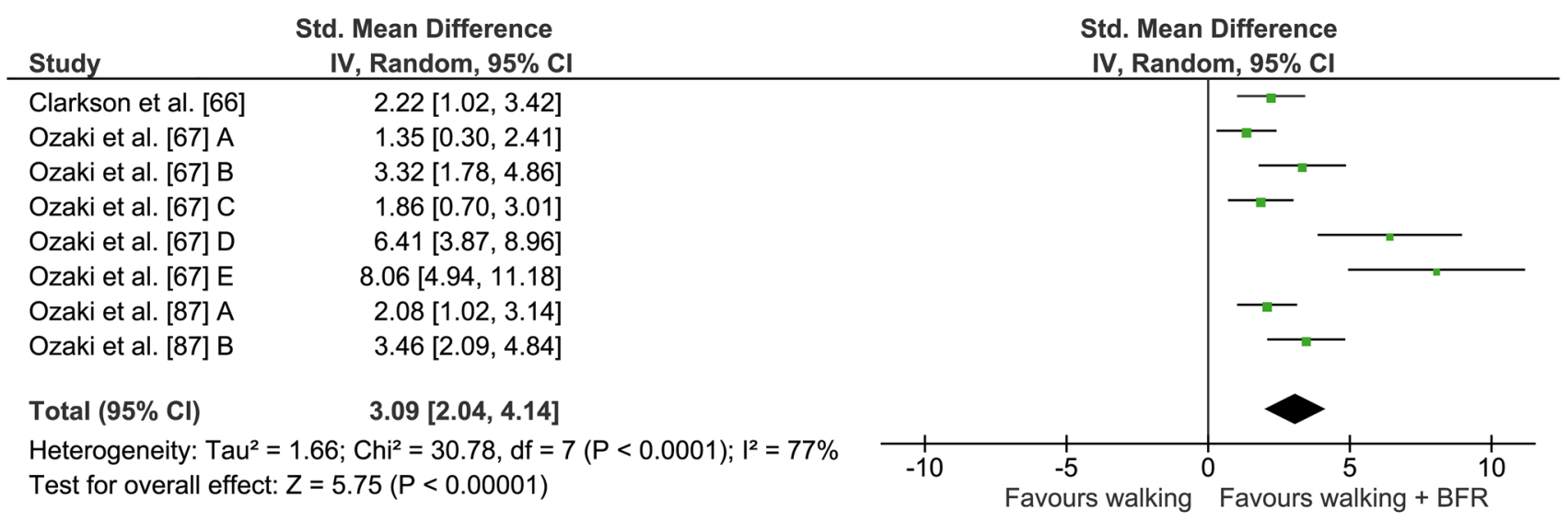

Fig. 5 Forest plot demonstrating the effects of walking + BFR versus normal walking on muscular strength. Different letters for the same study represent different muscular strength assessment methods. BFR blood flow restriction, $C I$ confidence interval, $I V$ inverse variance, Random random effects model

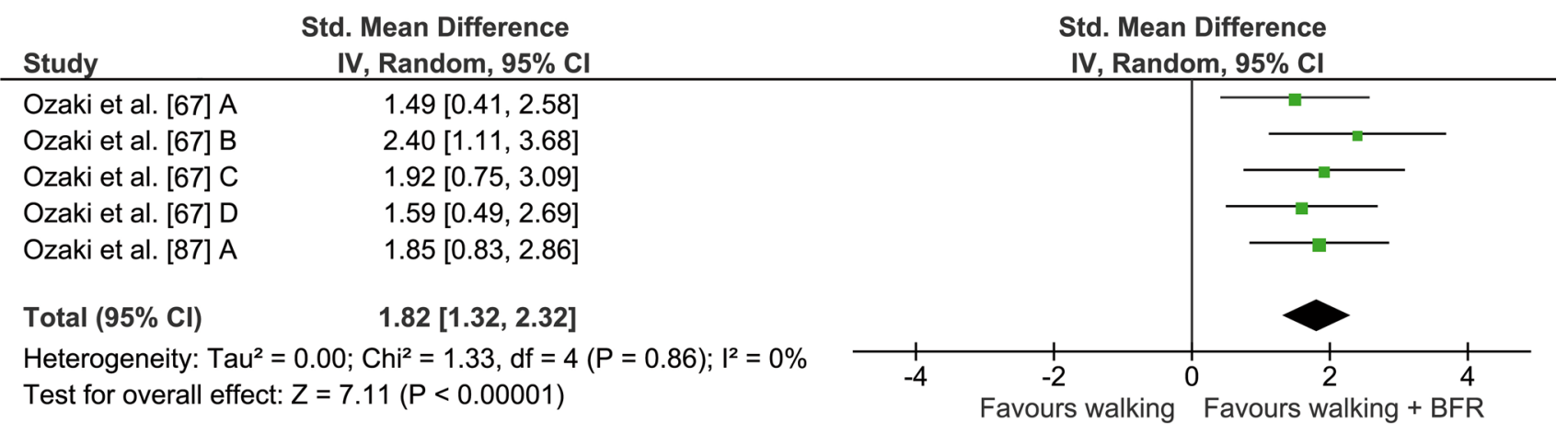

Fig. 6 Forest plot demonstrating the effects of walking + BFR versus normal walking on muscle mass. Different letters for the same study represent different muscle mass assessment methods. BFR blood flow

with conventional HL and LL training. In an additional analysis, we sought to provide insights into the beneficial effect of BFR combined with walking as this has particular implications for older individuals at risk of mobility limitations.

While our analyses demonstrate that HL and LL-BFR training produce similar increases in muscle mass in older cohorts, adaptations in muscular strength were smaller following LL-BFR training compared with those typically seen after HL training. However, the application of an external tourniquet seems to facilitate significantly greater responses in muscular strength compared with LL training alone. Due to insufficient data availability, no conclusion can be drawn about the effects of LL-BFR training on muscle mass compared with LL training alone. Interestingly, even during intensities as low as walking, BFR enhances strength and muscle mass adaptations in older subjects compared with normal walking. restriction, $C I$ confidence interval, $I V$ inverse variance, Random random effects model

\subsection{LL-BFR Versus HL Resistance Training}

Our results suggest that LL-BFR training is equally effective in increasing muscle mass but seems to be inferior in eliciting muscle strength responses compared with a common HL resistance training programme in older subjects. These findings are in line with a previously published meta-analysis by Lixandrao et al. [6], which investigated the effects of LL-BFR training and HL training in a mixed-age population.

Even though mechanical tension produced by LL-BFR training is assumed to be much lower than during HL training, our results indicate that gains in muscle mass were not different between these training protocols in older subjects. One plausible mechanism that has been reported to be as important as mechanical tension for the promotion of muscle mass is metabolic stress [36]. While one study demonstrated an augmented lactate concentration following LL-BFR compared with HL resistance training for older men [5], others 
showed inconsistent results [37]. Moreover, several studies reported that the intramuscular hypoxic environment and metabolic stress influence the fatigability of the muscle fibres and thus induce a progressive recruitment of motor units during training $[38,39]$. In addition to metabolic accumulation, the effects of LL-BFR on muscular hypertrophy have been suggested to be mediated by an increased mechanotransduction [40] and hormonal response [41], an acute production of reactive oxygen species [42] or cell swelling $[36,43]$. However, current research on this topic is sparse and studies investigating potential mechanisms are mostly performed with younger populations [39, 44, 45] or do not compare LL-BFR and HL resistance training [39, 40, 46]. Thus, any definite conclusions at this time would be premature.

The inferiority of LL-BFR resistance training in increasing muscular strength compared with traditional HL programmes could be linked to an insufficient neural drive during exercising with low loads. Studies investigating this aspect used surface electromyography (sEMG) or twitch interpolation to estimate changes in voluntary muscle activation during exercise. It was reported that EMG parameters (e.g. amplitude or integrated EMG) were greater following HL training than following LL-BFR training [47-49]. Kubo et al. [49], for example, showed that the activation levels of the quadriceps muscle assessed by sEMG and twitch interpolation significantly increased by $20.5 \%$ and $3.2 \%$, respectively, following 12-week HL training, with no significant changes in the LL-BFR group. However, these results must be interpreted with caution since a higher EMG amplitude might not necessarily represent a higher motor unit recruitment. Often the phenomenon of motor unit cycling, which refers to the fact that motor units can be temporarily derecruited for the purpose of reducing fatigue [50-52], is ignored by researchers. Moreover, these studies were conducted in young and healthy subjects $[48,49]$ and may not necessarily be transferred to older populations. However, the findings in these cohorts provide insights into how the observed results might be explained in older individuals.

\subsection{LL-BFR Versus LL Resistance Training}

Our finding that the addition of BFR to LL resistance training enhances muscle strength supports the results of a previous meta-analysis from Slysz et al. [1] that was conducted in mixed-aged populations. Functional adaptations in strength are generally believed to be mediated by neural (e.g. increased muscle activation) and/or structural factors (e.g. muscular hypertrophy) [53]. Evidence on this topic suggests that the application of a cuff during LL training is associated with a reduction in oxygen availability and high metabolite accumulation, thereby leading to significantly increased fasttwitch fibre recruitment $[38,39,54]$. However, studies with protocols to volitional exhaustion reported a similar muscle activation in both LL-BFR and LL groups [46, 48]. This supports the notion that LL alone can also elicit high levels of muscle activity (as assessed with sEMG) if the exercise task is performed in an all-out manner [46]. Accordingly, longterm intervention studies confirm that free-flow LL training performed to fatigue induces equal muscular hypertrophy compared with the same training with BFR [55]. Translating this to older individuals, performing resistance exercise to failure could increase the incidence of overtraining or musculoskeletal injuries compared with young individuals [56]. Therefore, the prescription of LL-BFR resistance training could be beneficial in these populations.

Besides neural changes with LL-BFR training, there seem to be structural changes when combining LL training with BFR in older people. Although two studies investigated the effects of LL-BFR in older individuals, both could not be included in the present meta-analysis due to insufficient study quality (PEDro < 4) [34] or unavailable raw data [5]. However, their findings point towards a significantly greater increase of muscle mass in the LL-BFR group compared with the LL group. Studies investigating the increase of muscle mass following LL-BFR in young individuals $[57,58]$ or athletes [59] confirm these results and show that LL-BFR maximizes the effects of LL training on muscle mass. These results, however, do not permit reliable statements for older populations.

Previous short-term studies provided evidence that the hypertrophic response is upregulated with partial vascular occlusion in older subjects. Fry et al. [40] investigated the effects of BFR training on stimulating mammalian target of rapamycin (mTOR) and muscle protein synthesis (MPS). Their results demonstrate that LL-BFR enhances mTOR signalling and MPS. Additionally, Fry and colleagues [40] observed a significant 9-fold growth hormone (GH) increase in the LL-BFR group compared with the control group. These findings are in accordance with other studies $[39,60]$, but have to be cautiously interpreted with regard to muscular hypertrophy, since muscle growth can occur even in the absence of key anabolic hormones such as insulin-like growth factor 1 or GH [61-64].

\subsection{BFR Walking Versus Normal Walking}

Although long-term walking training has been shown to increase muscle thickness and strength in the elderly [65], the present meta-analysis revealed that the combination of walking with BFR has significant additional benefits towards these outcomes. The percentage changes in muscular strength $(+13.3 \%)$ are comparable to what is seen after LL resistance training $(+12.3 \%)$. Changes in muscle mass are small but still significant $(+3.0 \%)$. Previous studies also report an increase in physical function [66], but not in 
aerobic capacity (estimated by peak oxygen uptake, $\mathrm{VO}_{2 \text { peak }}$ ) $[32,67]$.

Interestingly, a recent meta-analysis by Slysz et al. showed that the strength adaptations occur in an intensitydependent manner, with higher walking intensities $(>70 \mathrm{~m} /$ min) eliciting greater strength increases compared with lower intensities $(<70 \mathrm{~m} / \mathrm{min})$ [1]. Besides its positive effects on muscle mass and strength, walking combined with BFR has also been shown to improve venous compliance in untrained elderly subjects [68].

\subsection{Practical Implications}

Numerous studies have shown that the age-related loss of muscle strength is associated with a decrease in postural control [69] leading to a higher risk of falls [70] and mortality [71]. A frequently occurring simultaneous loss in muscle mass can contribute to the development of cardiometabolic diseases in the elderly [72]. This highlights the need for adequate interventions to counteract these phenomena in older age. To maximize the span of effective functioning for people with sarcopenia, Cruz-Jentoft et al. [73] suggest the use of multidimensional approaches combining physical exercise and nutritional interventions. However, current exercise guidelines for older people [74] are often difficult to implement due to contraindications to high training loads.

The fact that even low-workload walking exercise is able to facilitate such changes is of particular importance for older populations with limited functional capacity or mobility $[11,75]$. Maintaining fitness and an active lifestyle could thus help to postpone the crossing of the threshold for independence [76]. Apart from improvements on the muscular level, LL-BFR training has also been shown to positively influence bone metabolism and hence may be applicable in the prevention and treatment of bone diseases such as osteoporosis [77].

Given these musculoskeletal adaptations, LL-BFR training may be particularly recommended for older populations with contraindications regarding high training loads. For healthy individuals without contraindications, LL-BFR training may be prescribed in combination with HL training in order to aim for optimal muscular strength responses. From a practical standpoint, the data from our meta-analysis might help practitioners and therapists in geriatrics and rehabilitation to increase clients' functional capacity and maintain quality of life. In this regard, taking a thorough cardiovascular disease history from each individual is important to avoid adverse events, particularly since most risk factors have not been thoroughly investigated in older people. Kacin et al. [78] have developed a clinical screening tool for determining risk when prescribing BFR training programmes. These authors recommend a comprehensive assessment of personal, medical, social and family histories.

\subsection{Limitations and Strengths}

Regarding the interpretation of our results, there are some limitations in the present meta-analysis that should be mentioned. Although the field of BFR training is a frequently discussed topic in scientific research $[3,7,21,77]$, the number of studies investigating the effects of LL-BFR in older adults is still sparse. The limited number of included studies $(N=11)$ is not least attributable to the fact that we intentionally chose strict inclusion criteria in terms of study quality (PEDro > 4). It must also be noted that the study quality of the majority of included studies (10/11) was only rated as moderate $($ PEDro $=4)$. One main factor for potential bias and thus restricted study quality in all studies was the lack of subject blinding. While we are aware that it is not always feasible in BFR training interventions, future investigations should aim to choose different training locations in order to reduce performance bias. In addition, a large heterogeneity was found across studies for the comparisons of BFR with LL $\left(I^{2}=64\right)$ and walking $\left(I^{2}=77 \%\right)$ in muscular strength assessments. This large variability might result from differences in training protocols (i.e. training durations from 4 to 10 weeks), sample sizes, trained limbs (i.e. lower vs upper extremity) and strength assessments (dynamic 1RM vs isometric vs isokinetic testing). Furthermore, considering multiple outcomes from the same study in one meta-analysis could also partially have an impact on the homogeneity of the results.

\section{Conclusion}

The present systematic review and meta-analysis provides novel insights into the effect of LL-BFR training compared with training modalities that are currently used for counteracting the age-related decline in muscle mass and function. Our results indicate that the application of BFR to LL training and walking exercise positively influences muscular adaptations compared with each exercise under normal blood-flow conditions. In comparison with HL training, LLBFR elicits lower strength increases.

Although the research on this topic is limited, our data provide first evidence for practitioners and physicians that are confronted with individuals that cannot tolerate near-maximum loads but are in need of adequate therapy. Although previous surveys and reviews report an acceptable level of safety for LL-BFR for mixed age populations $[79,80]$, we recommend a thorough screening and physical examination of all trainees before commencing this training regimen. Although it was beyond the scope 
of this review, future studies need to examine potential moderators (e.g. cuff pressure, sex, volume or frequency) that might affect adaptations of muscle mass and strength in older adults. Additionally, we want to draw attention to the lack of high-quality studies comparing the effects of LL-BFR and LL on muscle mass.

Data Availability Statement The datasets generated and analysed during the current systematic review and meta-analysis are available from the corresponding author on reasonable request.

Acknowledgements The authors thank Christina Ramsenthaler (Department of Sport and Sport Science, Freiburg) for statistical assistance.

\section{Compliance with Ethical Standards}

Funding No sources of funding were used to assist in the preparation of this article.

Conflict of interest Christoph Centner, Patrick Wiegel, Albert Gollhofer and Daniel König declare that they have no conflict of interest relevant to the content of this review.

Open Access This article is distributed under the terms of the Creative Commons Attribution 4.0 International License (http://creativeco mmons.org/licenses/by/4.0/), which permits unrestricted use, distribution, and reproduction in any medium, provided you give appropriate credit to the original author(s) and the source, provide a link to the Creative Commons license, and indicate if changes were made.

\section{References}

1. Slysz J, Stultz J, Burr JF. The efficacy of blood flow restricted exercise: a systematic review \& meta-analysis. J Sci Med Sport. 2016;19(8):669-75. https://doi.org/10.1016/j.jsams 2015.09.005.

2. Hughes L, Paton B, Rosenblatt B, Gissane C, Patterson SD. Blood flow restriction training in clinical musculoskeletal rehabilitation: a systematic review and meta-analysis. Br J Sports Med. 2017;51(13):1003-11. https://doi.org/10.1136/bjsports-2016097071.

3. Scott BR, Loenneke JP, Slattery KM, Dascombe BJ. Exercise with blood flow restriction: an updated evidence-based approach for enhanced muscular development. Sports Med. 2015;45(3):31325. https://doi.org/10.1007/s40279-014-0288-1.

4. Karabulut M, Abe T, Sato Y, Bemben MG. The effects of lowintensity resistance training with vascular restriction on leg muscle strength in older men. Eur J Appl Physiol. 2010;108(1):14755. https://doi.org/10.1007/s00421-009-1204-5.

5. Takarada T, Takazawa H, Sato Y, Takebayashi S, Tanaka Y, Ishii $\mathrm{N}$. Effects of resistance exercise combined with moderate vascular occlusion on muscular function in humans. J Appl Physiol. 2000;88:2097-106.

6. Lixandrao ME, Ugrinowitsch C, Berton R, Vechin FC, Conceicao MS, Damas F, et al. Magnitude of muscle strength and mass adaptations between high-load resistance training versus low-load resistance training associated with blood-flow restriction: a systematic review and meta-analysis. Sports Med. 2018;48(2):36178. https://doi.org/10.1007/s40279-017-0795-y.

7. Loenneke JP, Wilson JM, Marin PJ, Zourdos MC, Bemben MG Low intensity blood flow restriction training: a meta-analysis. Eur J Appl Physiol. 2012;112(5):1849-59. https://doi.org/10.1007/ s00421-011-2167-x.

8. Hoffman C, Rice D, Sung H. Persons with chronic conditions: their prevalence and costs. JAMA. 1996;276(18):1473-9. https:// doi.org/10.1001/jama.1996.03540180029029.

9. Gheno R, Cepparo JM, Rosca CE, Cotten A. Musculoskeletal disorders in the elderly. J Clin Imaging Sci. 2012;2:39. https:// doi.org/10.4103/2156-7514.99151.

10. Papa EV, Dong X, Hassan M. Skeletal muscle function deficits in the elderly: current perspectives on resistance training. J Nat Sci. 2017;3(1):e272.

11. English KL, Paddon-Jones D. Protecting muscle mass and function in older adults during bed rest. Curr Opin Clin Nutr Metab Care. 2010;13(1):34-9. https://doi.org/10.1097/MCO.0b013 e328333aa66.

12. Cruz-Jentoft AJ, Baeyens JP, Bauer JM, Boirie Y, Cederholm T, Landi F, et al. Sarcopenia: European consensus on definition and diagnosis: report of the European Working Group on Sarcopenia in Older People. Age Ageing. 2010;39(4):412-23. https://doi.org/10.1093/ageing/afq034.

13. Trombetti A, Reid KF, Hars M, Herrmann FR, Pasha E, Phillips EM, et al. Age-associated declines in muscle mass, strength, power, and physical performance: impact on fear of falling and quality of life. Osteoporosis Int Osteoporos Int. 2016;27(2):46371. https://doi.org/10.1007/s00198-015-3236-5.

14. Allen J, Morelli V. Aging and exercise. Clin Geriatr Med. 2011;27(4):661-71. https://doi.org/10.1016/j.cger.2011.07.010.

15. Lutz W, Sanderson W, Scherbov S. The coming acceleration of global population ageing. Nature. 2008;451:716. https://doi. org/10.1038/nature06516. https://www.nature.com/articles/ nature06516\#supplementary-information.

16. Forbes SC, Little JP, Candow DG. Exercise and nutritional interventions for improving aging muscle health. Endocrine. 2012;42(1):29-38. https://doi.org/10.1007/s12020-012-9676-1.

17. Wong PCH, Chia MYH, Tsou IYY, Wansaicheong GKL, Tan B, Wang JCK, et al. Effects of a 12-week exercise training programme on aerobic fitness, body composition, blood lipids and C-reactive protein in adolescents with obesity. Ann Acad Med Singap. 2008;37(4):286-93.

18. Tieland M, Dirks ML, van der Zwaluw N, Verdijk LB, van de Rest O, de Groot LCPGM, et al. Protein supplementation increases muscle mass gain during prolonged resistancetype exercise training in frail elderly people: a randomized, double-blind, placebo-controlled trial. J Am Med Dir Assoc. 2012;13(8):713-9. https://doi.org/10.1016/j.jamda.2012.05.020.

19. Maltais ML, Ladouceur JP, Dionne IJ. The effect of resistance training and different sources of postexercise protein supplementation on muscle mass and physical capacity in sarcopenic elderly men. J Strength Cond Res. 2016;30(6):1680-7. https:// doi.org/10.1519/JSC.0000000000001255.

20. Melov S, Tarnopolsky MA, Beckman K, Felkey K, Hubbard A. Resistance exercise reverses aging in human skeletal muscle. PLoS One. 2007;2(5):e465. https://doi.org/10.1371/journ al.pone. 0000465 .

21. Scott BR, Loenneke JP, Slattery KM, Dascombe BJ. Blood flow restricted exercise for athletes: a review of available evidence. J Sci Med Sport. 2016;19(5):360-7. https://doi.org/10.1016/j. jsams.2015.04.014. 
22. Moher D, Liberati A, Tetzlaff J, Altman DG, Group P. Preferred reporting items for systematic reviews and meta-analyses: the PRISMA statement. Ann Intern Med. 2009;151(4):264-9, W64.

23. Stern C, Jordan Z, McArthur A. Developing the review question and inclusion criteria. Am J Nurs. 2014;114(4):53-6. https:// doi.org/10.1097/01.NAJ.0000445689.67800.86.

24. CRD. Systematic Reviews: CRD's Guidance for Undertaking Reviews in Health Care. York: CRD, University of York; 2006.

25. Verhagen AP, de Vet HC, de Bie RA, Kessels AG, Boers M, Bouter LM, et al. The Delphi list: a criteria list for quality assessment of randomized clinical trials for conducting systematic reviews developed by Delphi consensus. J Clin Epidemiol. 1998;51(12):1235-41.

26. Higgins JPT, Green S. Cochrane handbook for systematic reviews of interventions version 5.1.0 [updated march 2011]. The Cochrane Collaboration; 2015.

27. Borenstein M, Hedges LV, Higgins JPT, Rothstein HR. Introduction to meta-analysis. West Sussex: Wiley; 2009.

28. Hagger MS. Meta-analysis in sport and exercise research: review, recent developments, and recommendations. Eur J Sport Sci. 2006;6(2):103-15. https://doi.org/10.1080/17461390500528527.

29. Yokokawa Y, Hongo M, Urayama H, Nishimura T, Kai I. Effects of low-intensity resistance exercise with vascular occlusion on physical function in healthy elderly people. Biosci Trends. 2008;2(3):117-23.

30. Araujo JP, Neto GR, Loenneke JP, Bemben MG, Laurentino GC, Batista $\mathrm{G}$, et al. The effects of water-based exercise in combination with blood flow restriction on strength and functional capacity in post-menopausal women. Age. 2015;37(6). https://doi. org/10.1007/s11357-015-9851-4.

31. Yasuda T, Fukumura K, Fukuda T, Uchida Y, Iida H, Meguro M, et al. Muscle size and arterial stiffness after blood flow-restricted low-intensity resistance training in older adults. Scand J Med Sci Sports. 2014;24(5):799-806. https://doi.org/10.1111/sms.12087.

32. Abe T, Sakamaki M, Fujita S, Ozaki H, Sugaya M, Sato Y, et al. Effects of low-intensity walk training with restricted leg blood flow on muscle strength and aerobic capacity in older adults. J Geriatr Phys Ther. 2010;33(1):34-40.

33. Yasuda T, Fukumura K, Tomaru T, Nakajima T. Thigh muscle size and vascular function after blood flow-restricted elastic band training in older women. Oncotarget. 2016;7(23):33595-607. https:// doi.org/10.18632/oncotarget.9564.

34. Yasuda T, Fukumura K, Uchida Y, Koshi H, Iida H, Masamune K, et al. Effects of low-load, elastic band resistance training combined with blood flow restriction on muscle size and arterial stiffness in older adults. J Gerontol A Biol Sci Med Sci. 2015;70(8):950-8. https://doi.org/10.1093/gerona/glu084.

35. Kim J, Lang JA, Pilania N, Franke WD. Effects of blood flow restricted exercise training on muscular strength and blood flow in older adults. Exp Gerontol. 2017;99:127-32. https://doi. org/10.1016/j.exger.2017.09.016.

36. Pearson SJ, Hussain SR. A review on the mechanisms of bloodflow restriction resistance training-induced muscle hypertrophy. Sports Med. 2015;45(2):187-200. https://doi.org/10.1007/s4027 9-014-0264-9.

37. Pinto RR, Karabulut M, Poton R, Polito MD. Acute resistance exercise with blood flow restriction in elderly hypertensive women: haemodynamic, rating of perceived exertion and blood lactate. Clin Physiol Funct Imaging. 2018;38(1):17-24. https:// doi.org/10.1111/cpf.12376.

38. Moritani T, Sherman WM, Shibata M, Matsumoto T, Shinohara M. Oxygen availability and motor unit activity in humans. Eur J Appl Physiol Occup Physiol. 1992;64(6):552-6.

39. Takarada Y, Nakamura Y, Aruga S, Onda T, Miyazaki S, Ishii $\mathrm{N}$. Rapid increase in plasma growth hormone after low-intensity resistance exercise with vascular occlusion. J Appl Physiol. 2000;88(1):61-5.

40. Fry CS, Glynn EL, Drummond MJ, Timmerman KL, Fujita S, Abe $\mathrm{T}$, et al. Blood flow restriction exercise stimulates mTORC1 signaling and muscle protein synthesis in older men. J Appl Physiol (1985). 2010;108(5):1199-209. https://doi.org/10.1152/japplphysi ol.01266.2009.

41. Manini TM, Yarrow JF, Buford TW, Clark BC, Conover CF, Borst $\mathrm{SE}$. Growth hormone responses to acute resistance exercise with vascular restriction in young and old men. Growth Horm IGF Res. 2012;22(5):167-72. https://doi.org/10.1016/j.ghir.2012.05.002.

42. Centner C, Zdzieblik D, Dressler P, Fink B, Gollhofer A, Konig D. Acute effects of blood flow restriction on exercise-induced free radical production in young and healthy subjects. Free Radic Res. 2018;52(4):446-54. https://doi.org/10.1080/10715 762.2018.1440293.

43. Loenneke JP, Fahs CA, Rossow LM, Abe T, Bemben MG. The anabolic benefits of venous blood flow restriction training may be induced by muscle cell swelling. Med Hypotheses. 2012;78(1):151-4. https://doi.org/10.1016/j.mehy.2011.10.014.

44. Fujita S, Abe T, Drummond MJ, Cadenas JG, Dreyer HC, Sato $\mathrm{Y}$, et al. Blood flow restriction during low-intensity resistance exercise increases S6K1 phosphorylation and muscle protein synthesis. J Appl Physiol (1985). 2007;103(3):903-10. https://doi. org/10.1152/japplphysiol.00195.2007.

45. Nielsen JL, Aagaard P, Bech RD, Nygaard T, Hvid LG, Wernbom M, et al. Proliferation of myogenic stem cells in human skeletal muscle in response to low-load resistance training with blood flow restriction. J Physiol. 2012;590(17):4351-61. https:// doi.org/10.1113/jphysiol.2012.237008.

46. Wernbom M, Jarrebring R, Andreasson MA, Augustsson J. Acute effects of blood flow restriction on muscle activity and endurance during fatiguing dynamic knee extensions at low load. J Strength Cond Res. 2009;23(8):2389-95. https://doi.org/10.1519/ JSC.0b013e3181bc1c2a.

47. Manini TM, Clark BC. Blood flow restricted exercise and skeletal muscle health. Exerc Sport Sci Rev. 2009;37(2):78-85. https://doi. org/10.1097/JES.0b013e31819c2e5c.

48. Cook SB, Murphy BG, Labarbera KE. Neuromuscular function after a bout of low-load blood flow-restricted exercise. Med Sci Sports Exerc. 2013;45(1):67-74. https://doi.org/10.1249/ MSS.0b013e31826c6fa8.

49. Kubo K, Komuro T, Ishiguro N, Tsunoda N, Sato Y, Ishii N, et al. Effects of low-load resistance training with vascular occlusion on the mechanical properties of muscle and tendon. J Appl Biomech. 2006;22(2):112-9.

50. Westad C, Westgaard RH, De Luca CJ. Motor unit recruitment and derecruitment induced by brief increase in contraction amplitude of the human trapezius muscle. J Physiol. 2003;552(Pt 2):645-56. https://doi.org/10.1113/jphysiol.2003.044990.

51. Vigotsky AD, Beardsley C, Contreras B, Steele J, Ogborn D, Phillips SM. Greater electromyographic responses do not imply greater motor unit recruitment and 'hypertrophic potential' cannot be inferred. J Strength Cond Res. 2015. https://doi.org/10.1519/ jsc.0000000000001249.

52. Vigotsky AD, Halperin I, Lehman GJ, Trajano GS, Vieira TM. Interpreting signal amplitudes in surface electromyography studies in sport and rehabilitation sciences. Front Physiol. 2018;8(985). https://doi.org/10.3389/fphys.2017.00985.

53. Moritani T, deVries HA. Neural factors versus hypertrophy in the time course of muscle strength gain. Am J Phys Med. 1979;58(3):115-30.

54. Yasuda T, Fukumura K, Fukuda T, Iida H, Imuta H, Sato Y, et al. Effects of low-intensity, elastic band resistance exercise combined with blood flow restriction on muscle activation. Scand 
J Med Sci Sports. 2014;24(1):55-61. https://doi.org/10.111 1/j.1600-0838.2012.01489.x.

55. Farup J, de Paoli F, Bjerg K, Riis S, Ringgard S, Vissing K. Blood flow restricted and traditional resistance training performed to fatigue produce equal muscle hypertrophy. Scand J Med Sci Sports. 2015;25(6):754-63. https://doi.org/10.1111/sms.12396.

56. Stone MH, Chandler TJ, Conley MS, Kramer JB, Stone ME. Training to muscular failure: is it necessary? Strength Cond J. 1996;18(3):44-8.

57. Madarame H, Neya M, Ochi E, Nakazato K, Sato Y, Ishii N. Cross-transfer effects of resistance training with blood flow restriction. Med Sci Sports Exerc. 2008;40(2):258-63. https:// doi.org/10.1249/mss.0b013e31815c6d7e.

58. Yasuda T, Abe T, Sato Y, Midorikawa T, Kearns CF, Inoue K, et al. Muscle fiber cross-sectional area is increased after two weeks of twice daily KAATSU-resistance training. Int J KAATSU Training Res. 2005;1(2):65-70. https://doi.org/10.3806/ijktr.1.65.

59. Takarada Y, Sato Y, Ishii N. Effects of resistance exercise combined with vascular occlusion on muscle function in athletes. Eur J Appl Physiol. 2002;86(4):308-14.

60. Patterson SD, Leggate M, Nimmo MA, Ferguson RA. Circulating hormone and cytokine response to low-load resistance training with blood flow restriction in older men. Eur J Appl Physiol. 2013;113(3):713-9. https://doi.org/10.1007/s00421-012-2479-5.

61. West DW, Kujbida GW, Moore DR, Atherton P, Burd NA, Padzik JP, et al. Resistance exercise-induced increases in putative anabolic hormones do not enhance muscle protein synthesis or intracellular signalling in young men. J Physiol. 2009;587(Pt 21):5239-47. https://doi.org/10.1113/jphysiol.2009.177220.

62. Mitchell CJ, Churchward-Venne TA, Bellamy L, Parise G, Baker SK, Phillips SM. Muscular and systemic correlates of resistance training-induced muscle hypertrophy. PLoS One. 2013;8(10):e78636. https://doi.org/10.1371/journal.pone.0078636.

63. Walker KS, Kambadur R, Sharma M, Smith HK. Resistance training alters plasma myostatin but not IGF-1 in healthy men. Med Sci Sports Exerc. 2004;36(5):787-93.

64. Morton RW, Oikawa SY, Wavell CG, Mazara N, McGlory C, Quadrilatero J, et al. Neither load nor systemic hormones determine resistance training-mediated hypertrophy or strength gains in resistance-trained young men. J Appl Physiol (1985). 2016;121(1):12938. https://doi.org/10.1152/japplphysiol.00154.2016.

65. Kubo K, Ishida Y, Suzuki S, Komuro T, Shirasawa H, Ishiguro N, et al. Effects of 6 months of walking training on lower limb muscle and tendon in elderly. Scand J Med Sci Sports. 2008;18(1):31-9. https://doi.org/10.1111/j.1600-0838.2007.00654.x.

66. Clarkson MJ, Conway L, Warmington SA. Blood flow restriction walking and physical function in older adults: a randomized control trial. J Sci Med Sport. 2017;20(12):1041-6. https://doi. org/10.1016/j.jsams.2017.04.012.

67. Ozaki H, Sakamaki M, Yasuda T, Fujita S, Ogasawara R, Sugaya $\mathrm{M}$, et al. Increases in thigh muscle volume and strength by walk training with leg blood flow reduction in older participants. J Gerontol A Biol Sci Med Sci. 2011;66(3):257-63. https://doi. org/10.1093/gerona/glq182.

68. Iida H, Nakajima T, Kurano M, Yasuda T, Sakamaki M, Sato $\mathrm{Y}$, et al. Effects of walking with blood flow restriction on limb venous compliance in elderly subjects. Clin Physiol Funct Imaging. 2011;31(6):472-6. https://doi.org/10.1111/j.1475097X.2011.01044.X.

69. Wolfson L, Judge J, Whipple R, King M. Strength is a major factor in balance, gait, and the occurrence of falls. J Gerontol A Biol Sci Med Sci. 1995;50 Spec No:64-7.

70. Moreland JD, Richardson JA, Goldsmith CH, Clase CM. Muscle weakness and falls in older adults: a systematic review and metaanalysis. J Am Geriatr Soc. 2004;52(7):1121-9. https://doi.org/1 0.1111/j.1532-5415.2004.52310.x.
71. Cooper R, Kuh D, Hardy R, Mortality Review G, Falcon, Teams HAS. Objectively measured physical capability levels and mortality: systematic review and meta-analysis. BMJ. 2010;341:c4467. https://doi.org/10.1136/bmj.c4467.

72. Koopman R, van Loon LJ. Aging, exercise, and muscle protein metabolism. J Appl Physiol (1985). 2009;106(6):2040-8. https:// doi.org/10.1152/japplphysiol.91551.2008.

73. Cruz-Jentoft AJ, Landi F, Schneider SM, Zuniga C, Arai H, Boirie $\mathrm{Y}$, et al. Prevalence of and interventions for sarcopenia in ageing adults: a systematic review. Report of the International Sarcopenia Initiative (EWGSOP and IWGS). Age Ageing. 2014;43(6):748-59. https://doi.org/10.1093/ageing/afu115.

74. ACSM. American College of Sports Medicine position stand. Progression models in resistance training for healthy adults. Med Sci Sports Exerc. 2009;41(3):687-708. https://doi.org/10.1249/ mss.0b013e3181915670.

75. Paterson DH, Jones GR, Rice CL. Ageing and physical activity: evidence to develop exercise recommendations for older adults. Can J Public Health. 2007;98(Suppl 2):S69-108.

76. Lancet. Physical activity in old age. Lancet. 1986;328(8521):1431. https://doi.org/10.1016/S0140-6736(86)92740-6.

77. Bittar ST, Pfeiffer PS, Santos HH, Cirilo-Sousa MS. Effects of blood flow restriction exercises on bone metabolism: a systematic review. Clin Physiol Funct Imaging. 2018. https://doi.org/10.1111/cpf.12512.

78. Kacin A, Rosenblatt B, Grapar Zargi T, Biswas A. Safety considerations with blood flow restricted resistance training. Annales Kinesiologiae. 2015;6:26.

79. Loenneke JP, Wilson JM, Wilson GJ, Pujol TJ, Bemben MG. Potential safety issues with blood flow restriction training. Scand J Med Sci Sports. 2011;21(4):510-8. https://doi.org/10.111 $1 /$ j.1600-0838.2010.01290.x.

80. Nakajima T, Kurano M, Iida H, Takano H, Oonuma H, Morita T, et al. Use and safety of KAATSU training: results of a national survey. Int J KAATSU Train Res. 2006;2:5-13.

81. Cook SB, LaRoche DP, Villa MR, Barile H, Manini TM. Blood flow restricted resistance training in older adults at risk of mobility limitations. Exp Gerontol. 2017;99:138-45. https://doi. org/10.1016/j.exger.2017.10.004.

82. Libardi CA, Chacon-Mikahil MP, Cavaglieri CR, Tricoli V, Roschel H, Vechin FC, et al. Effect of concurrent training with blood flow restriction in the elderly. Int J Sports Med. 2015;36(5):395-9. https://doi.org/10.1055/s-0034-1390496.

83. Patterson SD, Ferguson RA. Enhancing strength and postocclusive calf blood flow in older people with training with blood-flow restriction. J Aging Phys Activ. 2011;19(3):201-2013.

84. Shimizu R, Hotta K, Yamamoto S, Matsumoto T, Kamiya K, Kato $\mathrm{M}$, et al. Low-intensity resistance training with blood flow restriction improves vascular endothelial function and peripheral blood circulation in healthy elderly people. Eur J Appl Physiol. 2016;116(4):749-57. https://doi.org/10.1007/s00421-016-3328-8.

85. Thiebaud RS, Loenneke JP, Fahs CA, Rossow LM, Kim D, Abe $\mathrm{T}$, et al. The effects of elastic band resistance training combined with blood flow restriction on strength, total bone-free lean body mass and muscle thickness in postmenopausal women. Clin Physiol Funct Imaging. 2013;33(5):344-52. https://doi.org/10.1111/ cpf.12033.

86. Vechin FC, Libardi CA, Conceicao MS, Damas FR, Lixandrao $\mathrm{ME}$, Berton RP, et al. Comparisons between low-intensity resistance training with blood flow restriction and high-intensity resistance training on quadriceps muscle mass and strength in elderly. J Strength Cond Res. 2015;29(4):1071-6. https://doi.org/10.1519/ jsc.0000000000000703.

87. Ozaki H, Miyachi M, Nakajima T, Abe T. Effects of 10 weeks walk training with leg blood flow reduction on carotid arterial compliance and muscle size in the elderly adults. Angiology. 2011;62(1):81-6. https://doi.org/10.1177/0003319710375942. 